\title{
Mijn Positieve Gezondheid en de Zelfredzaamheid-Matrix
}

\author{
Francisca Flinterman · Steve Lauriks · Matty de Wit · Stephan Cremer · Thijs Fassaert · Arnoud Verhoeff • \\ José Manshanden
}

Published online: 12 November 2019

(C) The Author(s) 2019

Met de opkomst van het concept Positieve Gezondheid en het daarbij behorende gespreksinstrument Mijn Positieve Gezondheid rijzen er vragen over hoe dit instrument zich verhoudt tot de Zelfredzaamheid-Matrix. Beide instrumenten geven een indicatie van het functioneren van mensen op een brede set gezondheidsdimensies of levensdomeinen [1-5]. Deze twee instrumenten, hoewel voor een verschillende context ontwikkeld, worden binnen het sociale domein in toenemende mate door elkaar gebruikt. Ze zijn echter geenszins onderling inwisselbaar. Omdat wij in Amsterdam meerdere malen geconfronteerd zijn met oneigenlijk gebruik van een van beide instrumenten gaan we in dit artikel dieper in op de specifieke toepassingsmogelijkheden, c.q. beperkingen van beide instrumenten.

\section{Mijn Positieve Gezondheid}

Mijn Positieve Gezondheid (MPG; www.mijnpositieve gezondheid.nl) is een gespreksinstrument, ontwikkeld om binnen een (medische) zorgcontext het brede gesprek met een cliënt aan te gaan en de cliënt zo veel mogelijk te activeren en eigen regie te geven. Het instrument is voortgekomen uit een stakeholderonder-

F. Flinterman $(\bowtie) \cdot S$. Lauriks $\cdot$ M. de Wit $\cdot$ S. Cremer Afdeling Epidemiologie, Gezondheidsbevordering en Zorginnovatie GGD Amsterdam, Amsterdam, Nederland fflinterman@ggd.amsterdam.nl

\section{T. Fassaert}

Afdeling Maatschappelijke en Geestelijke Gezondheidszorg, GGD Amsterdam, Amsterdam, Nederland

\section{A. Verhoeff}

Sarphati Amsterdam, research for healthy living,

GGD Amsterdam, Amsterdam, Nederland

J. Manshanden

Afdeling Directie, GGD Amsterdam, Amsterdam, Nederland zoek naar de indicatoren van gezondheid volgens het nieuwe concept van 'het vermogen om je aan te passen en je eigen regie te voeren in het licht van de fysieke, emotionele en sociale uitdagingen van het leven' [6]. Die indicatoren zijn gecategoriseerd in zes dimensies, die onderling verbonden zijn [1, 2]. In het gespreksinstrument worden de dimensies als assen van een spinnenweb weergegeven (zie fig. 1). Aan elke dimensie zijn zeven aspecten gekoppeld, die de inhoud van de dimensie toelichten.

Het MPG-gesprek gaat over de manier waarop de cliënt zelf zijn/haar functioneren op de verschillende dimensies waardeert en wat hij/zij anders wil. Bij het spinnenweb hoort een digitale vragenlijst met 42 vragen waarmee cliënten zichzelf voor het eigen functioneren op elk aspect een rapportcijfer kunnen geven. Per dimensie wordt aan de hand van die cijfers een gemiddeld cijfer berekend, dat in het spinnenweb wordt ingevuld. Ook kan het spinnenweb zonder vragenlijst ingevuld worden. Het gespreksinstrument wordt steeds breder binnen de zorg en het sociaal domein gebruikt. Het betreft een subjectieve zelfwaardering, waarmee MPG het bewustzijn van de cliënt ten aanzien van de eigen (positieve) gezondheid, de eigen kracht en kwetsbaarheden vergroot. Kern in het gesprek is vervolgens de vraag of de cliënt iets aan het eigen functioneren op de dimensies zou willen veranderen, wat dat dan zou zijn en waarom, waarmee MPG op zoek gaat naar de intrinsieke motivatie voor verandering. Doordat de cliënt zelf de behoefte aan en richting van een eventuele verandering aangeeft, vergroot MPG de eigen regie van de cliënt. Van de professional wordt verwacht een coachende houding aan te nemen en zijn/haar professionele oordeel op te schorten. Pas als de cliënt heeft aangegeven welke stappen hij/zij zou willen zetten, kan de professional vanuit zijn/haar expertise meedenken en adviseren. 

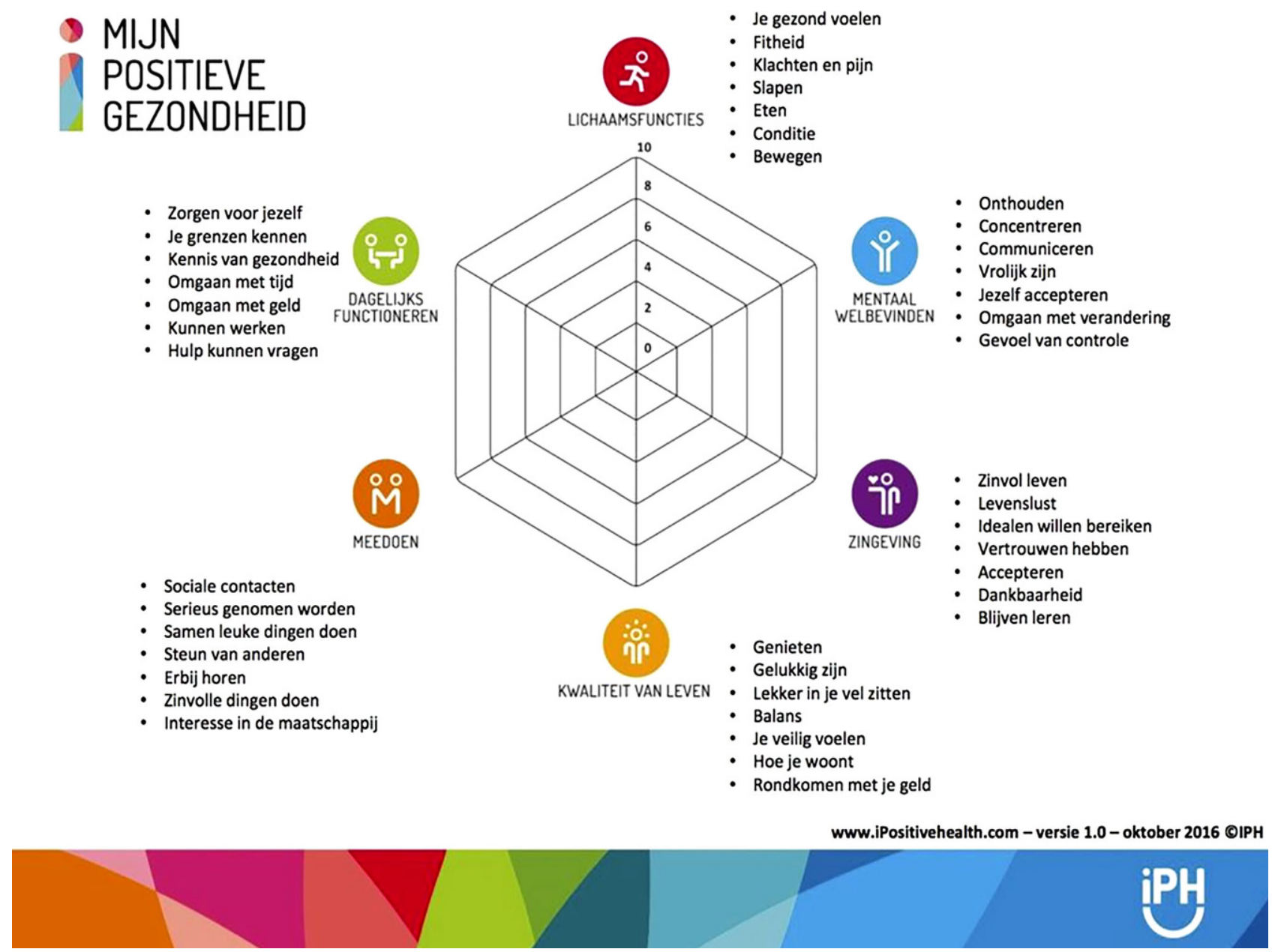

Figuur 1 Het gespreksinstrument Mijn Positieve Gezondheid

De vragen in de MPG-vragenlijst zijn niet gevalideerd, niet gekoppeld aan beoordelingscriteria en dus niet geschikt om het objectief functioneren van de client op de verschillende dimensies te onderzoeken of te meten. En in tegenstelling tot wat het geven van cijfers zou kunnen suggereren, kan de MPGvragenlijst ook niet gebruikt worden voor evaluatie- of monitoringsdoeleinden binnen een behandelof ondersteuningscontext. Daar is het instrument ook niet voor bedoeld. MPG beoogt in een open gesprek het perspectief en de intrinsieke motivatie van de cliënt bloot te leggen, als voorbereiding op (gedrags)verandering en/of de formulering van de ondersteuningsbehoefte.

Omdat er wel behoefte is aan een aan positieve gezondheid gerelateerd meetinstrument, wordt er momenteel hard gewerkt aan het verder conceptueel uitwerken en onderbouwen van het instrument. De huidige versie is conceptueel nog onvoldoende uitgewerkt gebleken om als basis te kunnen dienen voor de ontwikkeling van een meetinstrument [7]. Het gespreksinstrument MPG is continu in ontwikkeling. Varianten van MPG zijn de Kindtool voor kinderen tussen de 8 en 18 jaar, een jongerentool voor jongvol- wassenen tussen de 16 en 25 jaar en een eenvoudige tool voor laaggeletterden. Ook aan deze varianten zijn digitale vragenlijsten gekoppeld die door cliënten zelf in te vullen zijn.

\section{De Zelfredzaamheid-Matrix (ZRM)}

De ZRM (www.zelfredzaamheidmatrix.nl) is ontwikkeld in het kader van de openbare geestelijke gezondheidszorg om de zelfredzaamheid van een (kwetsbare) cliënt met betrekking tot de belangrijkste levensdomeinen in kaart te brengen. Inmiddels wordt de ZRM breed binnen het sociale domein gebruikt. Onder zelfredzaamheid wordt verstaan 'het realiseren van een acceptabel niveau van functioneren op de belangrijke domeinen van het dagelijks leven, indien nodig door de juiste hulp te organiseren op het moment dat een daling van het functioneringsniveau dreigt of plaatsvindt, die de persoon niet zelf kan voorkomen of verhelpen' [3-5]. Aan de hand van indicatoren geeft de professional een beoordeling van het functioneren van de cliënt op dertien levensdomeinen, op basis van een gesprek met de cliënt, zijn eigen observaties, informatie van derden en administratieve informatie- 
Figuur 2 Een voorbeeld van ZRM-scores van een cliënt bij instroom en bij uitstroom uit een interventie

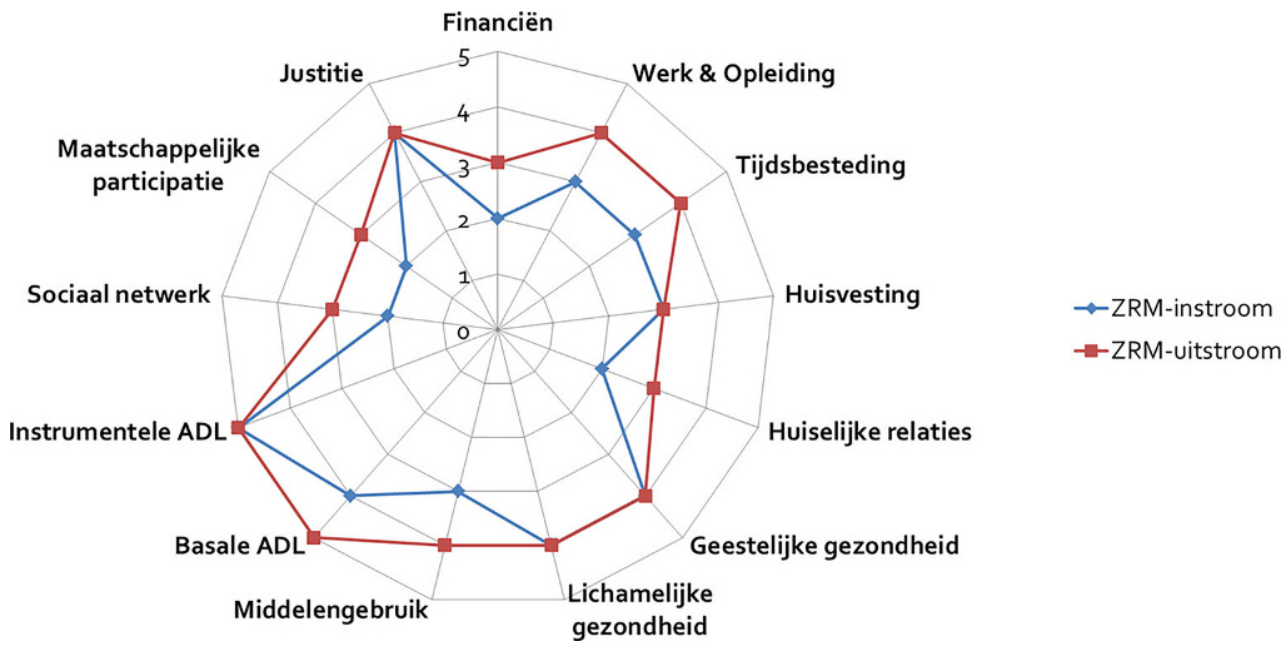

bronnen. In deze waardering neemt de professional ook de beleving van de cliënt mee, om die vervolgens te wegen op basis van een maatschappelijk en professioneel (normatief) kader. De ZRM is gevalideerd en heeft een voldoende interbeoordelaarsbetrouwbaarheid [8-10]. De ZRM meet zelfredzaamheid als een uitkomst, het observeerbare functioneren op het moment van beoordelen. Een voorbeeld van een ZRMbeoordeling van een cliënt bij instroom en uitstroom van een interventie is weergegeven in fig. 2 .

De ZRM draagt bij aan de professionalisering en bevordert het spreken van één taal binnen de multidisciplinaire hulpverleningsketens voor kwetsbare groepen. Tevens stimuleert ze het voeren van een breed gesprek met de cliënt en het transparant maken van beslissingen in de zorg en hulpverlening, en het vergelijken en monitoren van cliënten of groepen van cliënten voor casemanagement of beleid van een instelling of gemeente (bijvoorbeeld [11]).

De ZRM wordt iedere drie jaar doorontwikkeld op basis van feedback van professionals en cliënten, en wetenschappelijk onderzoek. Er zijn supplementen voor ouders en ouderen, en er is een ZRM voor huishoudens in de maak. Daarnaast is er een zelfrapportage-instrument: MijnZRM (www.mijnzrm.nl), waarmee een cliënt binnen het normatieve kader van de ZRM aan de hand van stellingen en vragen op de verschillende domeinen zijn eigen zelfredzaamheid in kaart kan brengen en in vrije tekst zijn eigen beleving en veranderwensen kan weergeven [12].

\section{MPG en de ZRM vergeleken}

In tab. 1 zijn beide instrumenten op verschillende aspecten vergeleken.

\section{Beschouwing}

De Zelfredzaamheid-Matrix en Mijn Positieve Gezondheid zijn twee elkaar aanvullende instrumenten die toegepast worden in de interactie tussen cliënt en professional. De ZRM is een objectief en normatief meetinstrument, terwijl MPG een instrument is voor een gesprek over de subjectieve beleving en de intrinsieke motivatie voor verandering. Ze hebben elk hun eigen toepassingsmogelijkheden en zijn niet inwisselbaar. Wel kunnen ze heel goed naast elkaar gebruikt worden. Het gespreksinstrument MPG kan bijvoorbeeld gebruikt worden voor het voeren van een open en breed gesprek waarin ook informatie voor het beoordelen van het functioneren met de ZRM wordt verzameld.

Een cliëntgesprek zou niet uitsluitend over de subjectieve beleving en ervaring van de cliënt, noch alleen maar over zijn/haar objectief functioneren moeten gaan. Beide aspecten zijn van belang om passende en effectieve zorg en ondersteuning te kunnen bieden.

Zowel de ZRM als MPG hebben naast hun sterke punten ook beperkingen. De ZRM is niet geschikt om een cliënt te motiveren en/of te activeren omdat het instrument niet aansluit bij de intrinsieke motivatie. Het blijkt soms zelfs averechts te kunnen werken als cliënten het gevoel krijgen 'in een hokje' geplaatst te worden. De ZRM geeft alleen informatie over het actuele functioneren van de cliënt. Informatie over cliëntwensen, cliëntdoelen, de ondersteuningsbehoefte en het aanbod, essentieel voor besluitvorming over te bieden zorg of ondersteuning, moet op een andere manier worden verzameld. MPG stelt daarentegen enige eisen aan het cognitief en reflectief vermogen van de cliënt. Cliënten die ernstig verward zijn of verstrikt zijn geraakt in hun eigen problematiek zullen niet in staat zijn haalbare veranderbehoeften te verwoorden. Verder zijn er vragen gesteld over de validiteit van de dimensies en indicatoren van MPG [7].

In relatie tot MPG en de ZRM maakt MijnZRM, als zelfbeoordelingsinstrument volgens een normatief kader, aangevuld met vragen over de beleving van het functioneren en veranderwensen, een derde weg mogelijk. Daarmee biedt MijnZRM binnen één instrument veel van de informatie die de ZRM en MPG ople- 
Tabel 1 Eigenschappen en toepassingen van MPG en de ZRM naast elkaar

\begin{tabular}{|c|c|c|}
\hline & Mijn Positieve Gezondheid & Zelfredzaamheid-Matrix \\
\hline doel & $\begin{array}{l}\text { brede gespreksvoering; zoeken naar cliëntperspectief en } \\
\text { intrinsieke motivatie, bevorderen van activering en eigen } \\
\text { regie }\end{array}$ & $\begin{array}{l}\text { objectieve beoordeling/screening en/of onderlinge vergelijking van het functio- } \\
\text { neren van cliënten op } 13 \text { levensdomeinen }\end{array}$ \\
\hline werkwijze & $\begin{array}{l}\text { open, breed gesprek langs de } 6 \text { dimensies: de client } \\
\text { waardeert het eigen functioneren op de dimensies zon- } \\
\text { der criteria; waar is hij/zij tevreden over en wat zou } \\
\text { hij/zij eventueel willen veranderen, en hoe? }\end{array}$ & $\begin{array}{l}\text { breed gesprek langs de } 13 \text { domeinen; aan de hand van de verkregen informatie } \\
\text { en een aantal criteria bepaalt de professional de scores op de domeinen }\end{array}$ \\
\hline validiteit & nee & ja, zowel criterium- als inhoudsvaliditeit \\
\hline betrouwbaarheid & nee & ja, interbeoordelaarsbetrouwbaarheid \\
\hline objectiviteit & subjectief & objectief; de ZRM meet de situatie aan de hand van vooraf gestelde normen \\
\hline cliëntperspectief & ja, het cliëntperspectief is leidend & beperkt \\
\hline $\begin{array}{l}\text { wanneer gebrui- } \\
\text { ken? }\end{array}$ & $\begin{array}{l}\text { - bij intake of bij vastlopen van een ondersteuningspro- } \\
\text { ces } \\
\text { - bij cliënten met enige mate van zelfinzicht en zelfre- } \\
\text { flectie } \\
\text { - ten behoeve van vraagverheldering en doelexplicite- } \\
\text { ring bij een cliënt } \\
\text { - ten behoeve van een cliënt } \\
\text { - ten behoeve van het aanspreken van de intrinsieke } \\
\text { motivatie en de activatie van een cliënt } \\
\text { - ten behoeve van de vergroting van de veerkracht en } \\
\text { de eigen regie van een cliënt }\end{array}$ & $\begin{array}{l}\text { - bij screening, intake, tussenevaluatie of uitstroom } \\
\text { - bij cliënten met (vermoeden op) problematiek op meerdere levensgebieden } \\
\text { - ten behoeve van het in kaart brengen van de zelfredzaamheid om richting te } \\
\text { geven aan (de intensiteit van) de hulpverlening } \\
\text { - ten behoeve van casemanagement (zorgcoördinatie), opstellen en aanpassen } \\
\text { van het behandelplan } \\
\text { - ten behoeve van transparantie van beslissingen met betrekking tot zorg- en } \\
\text { hulpverleningsaanbod } \\
\text { - ten behoeve van monitoring van cliëntpopulaties voor beleid en wetenschap } \\
\text { - ter evaluatie van de effectiviteit van interventies }\end{array}$ \\
\hline $\begin{array}{l}\text { wanneer niet } \\
\text { gebruiken? }\end{array}$ & $\begin{array}{l}\text { - bij behoefte aan een meet- of screeningsinstrument } \\
\text { - ten behoeve van monitoring } \\
\text { - ten behoeve van vergelijking tussen cliënten } \\
\text { - ter verantwoording van indicatie of bemoeizorg }\end{array}$ & $\begin{array}{l}\text { - bij slechts de wens van een cliëntgestuurd, open gesprek } \\
\text { - om de subjectieve behoeften en intrinsieke motivatie van cliënten in beeld te } \\
\text { krijgen } \\
\text { - bij behoefte aan diagnostiek ten behoeve van een specifieke (medische) } \\
\text { behandeling }\end{array}$ \\
\hline
\end{tabular}

veren. Dit kan het beste van twee werelden zijn, maar draagt ook het risico in zich twee onverenigbare aspecten (de normatieve beoordeling en de subjectieve beleving) te willen combineren. Nader onderzoek zou moeten uitwijzen wat de verschillen zijn in cliëntenperspectief tussen een volledig subjectieve beoordeling, zoals MPG, versus een combinatie met het normatieve instrument. MPG en de ZRM bieden volledig andere informatie over dezelfde onderwerpen, namelijk informatie over de subjectieve ervaring van het functioneren op de belangrijkste domeinen van het leven, en over het objectieve, actuele functioneren op die levensdomeinen. Het is daarom waarschijnlijk dat de zelfwaardering met MPG een heel ander beeld van het functioneren geeft dan met de beoordeling van het functioneren op de ZRM wordt verkregen. Ook de op basis van MPG geuite veranderbehoefte van de cliënt zou behoorlijk kunnen verschillen van de met de ZRM gevonden zorgbehoefte. Door beide instrumenten naast elkaar te gebruiken en subjectieve ervaringen en intrinsieke motivatie naast objectieve waarnemingen te leggen is een verdieping van het gesprek tussen professional en cliënt mogelijk, en kan de meest passende, wenselijke en effectieve zorg en ondersteuning worden geboden, de ontwikkeling van het functioneren van de cliënt worden gevolgd en het aanbod worden geëvalueerd.

Open Access This article is distributed under the terms of the Creative Commons Attribution 4.0 International License (http://creativecommons.org/licenses/by/4.0/), which per- mits unrestricted use, distribution, and reproduction in any medium, provided you give appropriate credit to the original author(s) and the source, provide a link to the Creative Commons license, and indicate if changes were made.

\section{Literatuur}

1. Huber M. Naar een nieuw begrip van gezondheid: Pijlers voor Positieve Gezondheid. Tijdschr Gezondheidswet. 2013;91(3):133.

2. Huber M, Vliet M van, Giezenberg $M$, et al. Towards a 'patient-centred' operationalisation of the new dynamic concept of health: a mixed methods study. BMJ Open. 2016;5:e10091.

3. Lauriks S, Buster MCA, Wit MAS de, et al. ZelfredzaamheidMatrix 2010. Handleiding en toelichting bij de Zelfredzaamheid-Matrix 2010. Amsterdam: GGD Amsterdam; 2010.

4. Lauriks S, Buster MCA, Wit MAS de, et al. ZelfredzaamheidMatrix 2013; Zelfredzaamheid-Matrix 2013 Handleiding. Amsterdam: GGD Amsterdam; 2013.

5. Lauriks S, Buster MCA, Wit MAS de, et al. ZelfredzaamheidMatrix 2017 Handleiding Zelfredzaamheid-Matrix 2017. Amsterdam: GGDAmsterdam;2017.

6. Huber M, Knottnerus JA, Green L, et al. How should we define health? BMJ.2011;343:d4163.

7. Prinsen CAC, Terwee CB. Measuring positive health: for now, a bridge too far. Public Health. 2019;170:70-7.

8. Fassaert T, Lauriks S, Weerd S van de, et al. Ontwikkeling en betrouwbaarheidvan deZelfredzaamheid-Matrix. Tijdschr Gezondheidswet. 2013;91(3):169-77.

9. Fassaert T, Lauriks S, Weerd S van de, et al. Psychometric properties of the Dutch version of the self-sufficiencymatrix (SSM-D). Community Ment Health J. 2014;50:583-90. 


\section{Forum}

10. Boom W van den, Klaufus L, Fassaert T, et al. Psychometrische kenmerken van de Zelfredzaamheid-Matrix (ZRM) en het ZRM-Supplement Ouderschap. Kind Adolesc. 2016;37:105-19.

11. Lauriks S, Wit MAS de, Buster MCA, et al. The use of the Dutch self-sufficiency Matrix (SSM-D) to inform allocation decisions to public mental health care for homeless people. Community Ment Health J. 2014;50(7):870-8.

12. Boom W van den, Klaufus L, Lauriks S, et al. Scores op de Zelfredzaamheid-Matrix en MijnZRM vergeleken. Tijdschr Gezondheidswet. 2018;96(7):290-8. 